\title{
The effect of clove-based herbal mouthwash on radiation-induced oral mucositis in patients with head and neck cancer: a single-blind randomized preliminary study
}

\author{
This article was published in the following Dove Press journal: \\ OncoTargets and Therapy \\ 22 July 2016 \\ Number of times this article has been viewed
}

\section{Moonkyoo Kong' \\ Deok-Sang Hwang ${ }^{2}$ \\ Seong Woo Yoon ${ }^{3}$ \\ Jinsung $\mathrm{Kim}^{4}$}

'Department of Radiation Oncology, Kyung Hee University Medical Center, Kyung Hee University School of Medicine, ${ }^{2}$ Department of Korean Medicine Obstetrics \& Gynecology, Kyung Hee University Medical Center, ${ }^{3}$ Department of Korean Internal Medicine, Korean Medicine Cancer Center, Kyung Hee University Hospital at Gangdong, ${ }^{4}$ Department of Korean Internal Medicine, Kyung Hee University Medical Center, College of Korean Medicine, Kyung Hee University, Seoul, Republic of Korea
Correspondence: Seong Woo Yoon Department of Korean Internal Medicine, Korean Medicine Cancer Center, Kyung Hee University Hospital at Gangdong, I 49 Sangil-dong, Gangdong-gu, Seoul 130-090, Republic of Korea

Tel +82 24407272

Fax +82 24407287

Email stepano212@hanmail.net
Purpose: This study was performed to evaluate the efficacy and safety of clove-based herbal mouthwash in ameliorating radiation-induced oral mucositis in patients with head and neck cancer. Methods: Fourteen patients were prospectively enrolled in this study and randomized to either an experimental group or a control group. The patients of the experimental group swished their mouths with a clove-based herbal mouthwash during radiotherapy (RT), while the patients of the control group swished with clear water. The primary end point of this study was incidence of radiation-induced oral mucositis. The secondary end points were time to onset of radiationinduced oral mucositis, duration of radiation-induced oral mucositis, incidence of supplemental nutrition through feeding tube, maximum pain score, body weight loss, incidence of RT interruption, and duration of RT interruption.

Results: The use of clove-based herbal mouthwash shortened the duration of grade $\geq 2$ mucositis (24.3 days vs 37.1 days, $P=0.044)$ and reduced body weight loss during RT $(3.1 \%$ vs $7.4 \%$, $P=0.023$ ) compared with clear water. The use of clove-based herbal mouthwash also reduced the incidence of grade 3 mucositis ( $28.6 \%$ vs $57.1 \%$ ), supplemental nutrition ( $0 \%$ vs $28.6 \%$ ), and RT interruption ( $14.3 \%$ vs $28.6 \%$ ), and reduced the duration of grade 3 mucositis ( 5.1 days vs 17.7 days) and RT interruption ( 1 days vs 8.5 days). In addition, clove-based herbal mouthwash delayed the time to onset of mucositis (26.6 days vs 24.5 days) and reduced the maximum pain score (4.1 vs 4.9). However, these differences were not statistically significant.

Conclusion: Although we could not find significant differences in some end points, this singleblind randomized study showed that a clove-based herbal mouthwash can have a potentially beneficial effect on minimizing or preventing radiation-induced oral mucositis in patients with head and neck cancer. To confirm the results of our study, well-designed randomized studies with large sample sizes will be required.

Keywords: radiotherapy, mucositis, head and neck cancer, clove-based herbal mouthwash

\section{Introduction}

Radiotherapy (RT) plays an important role in the treatment of locally advanced head and neck cancer. Radiation-induced oral mucositis is the most common complication of RT and causes clinical and economic problems, in patients with head and neck cancer. ${ }^{1-4}$ Although many clinical studies attempting to reduce radiation-induced oral mucositis have been reported, there is no widely accepted effective agent for treatment of radiation-induced oral mucositis. ${ }^{5-13}$ 
Flos caryophylli (clove) based herbal mouthwash was originally prepared to inhibit halitosis and consists of clove, Fructus schisandrae, Radix glycyrrhizae, Magnolia officinalis, and Herba menthae. ${ }^{14}$ Several studies have reported that ingredients of clove-based herbal mouthwash show anti-inflammatory effects in both in vitro and in vivo models, ${ }^{15-24}$ and two cases were recently reported in which chemotherapy-induced oral mucositis was improved after using a clove-based herbal mouthwash. ${ }^{25}$ However, there are no reports on the effect of clove-based herbal mouthwash on radiation-induced oral mucositis. This study was performed to evaluate the efficacy and safety of clove-based herbal mouthwash in the amelioration of radiation-induced oral mucositis in patients with head and neck cancer.

\section{Materials and methods}

Patient eligibility criteria included presence of histologically confirmed head and neck cancer, treatment with RT either definitively or postoperatively, good general condition with performance status of $\leq 2$ in the Eastern Cooperative Oncology Group classification, no previous head and neck irradiation, and planned RT dose of $\geq 50$ Gy to two different subsites of the inspected oral cavity and oropharynx. Patients with poor oral hygiene or unhealed wounds in the oral cavity or oropharynx were excluded. Patients who received induction chemotherapy or were scheduled to receive concurrent chemotherapy were also excluded. The study was approved by the Institutional Review Board of Kyung Hee University Medical Center, and was conducted in compliance with the Declaration of Helsinki guidelines. We obtained written informed consent from all patients.

From May 2014 through May 2015, 14 patients were prospectively enrolled in this study and randomized to either the experimental group or the control group. The patients assigned to the experimental group were instructed to swish their mouths with $10 \mathrm{~mL}$ of clove-based herbal mouthwash for 1 minute and then expectorate. The gargling procedure was to be repeated four times (30 minutes before every meal and going to bed) each day, and practiced at the onset of RT until 2 weeks after completion of RT or until radiation-induced oral mucositis subsided. To prepare the herbal mouthwash, $8 \mathrm{~g}$ of $F$. caryophylli, $6 \mathrm{~g}$ of $F$. schisandrae, and $4 \mathrm{~g}$ each of $R$. glycyrrhizae, M. officinalis, and $H$. menthae were extracted twice with $80 \%$ ethanol. Extracts were concentrated, mixed with $200 \mathrm{~mL}$ water, and packaged in plastic bottles. Herbal mouthwash was standardized based on the contents of clove, F. schisandrae, R. glycyrrhizae, $M$. officinalis, and $H$. menthae equipped with ultraviolet
(UV) detector. ${ }^{14}$ The separation was carried out using Nucleosil ${ }^{\circledR} \mathrm{C}_{18}$ column with $4.0 \times 250 \mathrm{~mm}$ inner diameter, (Waters, Taunton, MA, USA) at $25^{\circ} \mathrm{C}$. The mobile phase was acetonitrile-water-acetic acid (50:50:1, v/v) at a flow rate of $0.8 \mathrm{~mL} / \mathrm{min}$. The detection wavelength was set at $254 \mathrm{~nm}$. The injection volume was $10 \mu \mathrm{L}$. Clove-based herbal mouthwash and reference to the calibration curve obtained with glycyrrhizin, eugenol, magnolol, and honokiol were analyzed in triplicate. Glycyrrhizin, eugenol, magnolol, and honokiol were found in clove-based herbal mouthwash at a mean level of 20, 0.9, 0.5, and $0.4 \mathrm{ppm}$, respectively. All herbs were purchased from Kyung Hee University Medical Center, and quality control of the preparation process was conducted according to Korean Good Manufacturing Practice. The solution was stored in a refrigerator, and shaking the bottle before administration was mandatory. Patients assigned to the control group were instructed to swish their mouths with $10 \mathrm{cc}$ of clear water. The clear water was purified using water purifier and stored in a refrigerator. The gargling procedure of the control group was identical to that of the experimental group. One of the investigators checked compliance with the instructions for the gargling procedure weekly and repeatedly instructed the volunteers of both groups to adhere to the gargling procedure every day. Any medications or mouthwash solutions for radiation-induced oral mucositis were not allowed in either group. All patients were also instructed to clean their teeth with a soft toothbrush three times a day (after every meal). If spontaneous gum bleeding occurred, they were instructed only to rinse their mouths with the study solutions (clove-based herbal mouthwash or clear water). All patients received pretreatment dietary counseling which was reinforced weekly. All patients also received pretreatment dental evaluation. A supplemental feeding tube for adequate nutrition was placed at the investigator's discretion.

All patients received computed tomography (CT)planned, intensity-modulated RT using simultaneous integrated boost technique. RT was carried out with a TomoTherapy ${ }^{\circledR}$ (TomoTherapy Inc., Madison, WI, USA) treatment system. The prescription dose was determined by the physician and based on the aims of treatment (definitively or postoperatively), tumor stage, and the patient's general condition. The total RT doses ranged from 57.2 to $70 \mathrm{~Gy}$, and the daily doses ranged from 2 to $2.35 \mathrm{~Gy}$.

Radiation-induced oral mucositis was examined at daily intervals from the start of RT until 8 weeks after its completion. The grade of radiation-induced oral mucositis was scored by one investigator (M Kong), on the upper and lower lips, right and left cheeks, right and left ventral and lateral side of the 
tongue, floor of mouth, soft and hard palates, and oropharynx, according to Radiation Therapy Oncology Group guidelines. The investigator was blinded to patient group assignment. This investigator was not involved in patient assignment or checking patients' compliance with the instructions for the gargling procedure. Therefore, we could maintain blinding throughout the study. The patients' evaluation of pain within the RT field was assessed with a $10 \mathrm{~cm}$ visual analog scale at daily intervals, and body weight was also checked weekly from the start of RT to 8 weeks after its completion. During treatment, RT interruptions and total number of treatment days lost were recorded. Any adverse events associated with clove-based herbal mouthwash were assessed at daily intervals from the start of RT until 4 weeks after its completion using Common Terminology Criteria for Adverse Events, version 4.0.

The primary end point of this study was incidence of radiation-induced oral mucositis. The secondary end points were time to onset of radiation-induced oral mucositis, duration of radiation-induced oral mucositis, incidence of supplemental nutrition through feeding tube, maximum pain score, body weight loss, incidence of RT interruption, and duration of RT interruption. Baseline characteristics of the two groups of patients were compared using the chisquare test or independent $t$-test. To assess differences in the incidence of radiation-induced oral mucositis, use of supplemental feeding tube, and RT interruption between the two groups, we compared actuarial rates estimated using the Kaplan-Meier method, and comparison between the groups was performed using the log-rank test. Elapsed time was calculated from the date of initiation of RT to the date of onset of events. Duration of radiation-induced oral mucositis and RT interruption, maximum pain score, and body weight loss were compared using the Mann-Whitney $U$-test. The duration of radiation-induced oral mucositis was calculated as the number of days from the onset of oral mucositis to the day when resolved. Patients who did not experience oral mucositis were assigned a duration of 0 days. Body weight loss was defined as the reduction ratio of body weight during treatment, and calculated as ([Body weight at the start of RT - Body weight at the completion of RT]/Body weight at the start of RT $) \times 100(\%)$. All analyses were performed using SPSS version 18.0 (IBM Corporation, Armonk, NY, USA), and $P<0.05$ was considered statistically significant.

\section{Results}

Patient characteristics are summarized in Table 1. There were no significant differences in patient or tumor characteristics between the two groups. One patient in the experimental
Table I Patient characteristics

\begin{tabular}{|c|c|c|c|}
\hline Characteristics & $\begin{array}{l}\text { Experimental } \\
\text { group } \\
(n=7)\end{array}$ & $\begin{array}{l}\text { Control } \\
\text { group } \\
(n=7)\end{array}$ & $P$-value \\
\hline \multicolumn{4}{|l|}{ Age (years) } \\
\hline Median (range) & $65.8(31.8-76.9)$ & $69.1(40.4-75.2)$ & 0.886 \\
\hline \multicolumn{4}{|c|}{ ECOG performance status } \\
\hline $0 / 1$ & $1 / 6$ & $0 / 7$ & 0.846 \\
\hline \multicolumn{4}{|l|}{ Sex } \\
\hline Male/female & $7 / 0$ & $6 / 1$ & 0.257 \\
\hline \multicolumn{4}{|l|}{ Diabetes mellitus } \\
\hline Yes/no & $2 / 5$ & $1 / 6$ & 0.987 \\
\hline \multicolumn{4}{|c|}{ Body mass index $\left(\mathrm{kg} / \mathrm{m}^{2}\right)$} \\
\hline Median (range) & $22.1(20.4-26.1)$ & $21.7(18.2-28.2)$ & 0.624 \\
\hline \multicolumn{4}{|l|}{ Smoking } \\
\hline Current smoker & 3 & 4 & 0.472 \\
\hline Former smoker & 4 & 2 & \\
\hline Never smoker & 0 & I & \\
\hline \multicolumn{4}{|l|}{ Alcohol } \\
\hline Current drinker & 3 & 4 & 0.267 \\
\hline Former drinker & 3 & 2 & \\
\hline Never drinker & I & I & \\
\hline \multicolumn{4}{|l|}{ Primary tumor site } \\
\hline Oral cavity & 3 & 3 & 0.827 \\
\hline Oropharynx & I & 2 & \\
\hline Parotid gland & I & I & \\
\hline Maxillary sinus & I & I & \\
\hline Unknown primary & I & 0 & \\
\hline \multicolumn{4}{|l|}{ Tumor stage } \\
\hline III & 0 & I & 0.834 \\
\hline IVA & 6 & 5 & \\
\hline IVB & I & I & \\
\hline \multicolumn{4}{|l|}{ Total RT dose (Gy) } \\
\hline Median (range) & $63(57.2-70)$ & $63(60-69.3)$ & 0.639 \\
\hline \multicolumn{4}{|l|}{ Daily RT dose (Gy) } \\
\hline Median (range) & $2.1(2-2.2)$ & $2.1(2-2.35)$ & 0.462 \\
\hline
\end{tabular}

Abbreviations: ECOG, Eastern Cooperative Oncology Group; RT, radiotherapy.

group experienced temporary RT interruption for 1 day because of oral pain. Two patients in the control group experienced RT interruption for 7 and 10 days, respectively, because of poor oral intake and oral pain. All patients in both groups completed scheduled RT regimen and complied well with the instructions for the gargling procedure. Therefore, all patients were included in the efficacy and safety analyses.

In the experimental group, two patients (28.6\%) experienced grade 3 radiation-induced oral mucositis at 36 and 37 days, respectively, from the date of initiation of RT. In comparison, four patients (57.1\%) experienced grade 3 mucositis at 20,22, 36, and 37 days, respectively, in the control group. The experimental group had a lower incidence of grade 3 radiation-induced oral mucositis than the control group (28.6\% vs $57.1 \%)$. However, this difference was not statistically significant $(P=0.184)$. All patients in both groups experienced grade $\geq 2$ radiation-induced oral mucositis. 
Table 2 Analysis of primary and secondary end points

\begin{tabular}{|c|c|c|c|}
\hline End point & Experimental group & Control group & $P$-value \\
\hline \multicolumn{4}{|l|}{ Incidence of oral mucositis (\%) } \\
\hline Grade 3 & 28.6 & 57.1 & 0.184 \\
\hline Grade $\geq 2$ & 100 & 100 & N/A \\
\hline \multicolumn{4}{|l|}{ Time to onset of oral mucositis (days) } \\
\hline Grade 3 & 36,37 & $20,22,36,37$ & N/A \\
\hline Grade 2 (mean $\pm S D)$ & $26.6 \pm 6.51$ & $24.5 \pm 8.09$ & 0.524 \\
\hline \multicolumn{4}{|l|}{ Duration of oral mucositis (days) } \\
\hline Grade $3($ mean \pm SD) & $5.1 \pm 8.80$ & $|7.7 \pm| 5.9 \mid$ & 0.069 \\
\hline Grade $\geq 2($ mean $\pm S D)$ & $24.3 \pm 8.00$ & $37.1 \pm 13.99$ & 0.044 \\
\hline Incidence of supplemental nutrition (\%) & 0 & 28.6 & 0.141 \\
\hline Pain score $($ mean $\pm S D)$ & $4.1 \pm 1.32$ & $4.9 \pm 1.1$ & 0.353 \\
\hline Body weight loss $(\%)$ (mean $\pm S D)$ & $3.1 \pm 2.42$ & $7.4 \pm 2.98$ & 0.023 \\
\hline Incidence of RT interruption (\%) & 14.3 & 28.6 & 0.470 \\
\hline Duration of RT interruption (days) (mean \pm SD) & I & $8.5 \pm 2.12$ & N/A \\
\hline
\end{tabular}

Abbreviations: N/A, not analyzed; RT, radiotherapy; SD, standard deviation.

The mean time to onset of grade 2 radiation-induced oral mucositis was 26.6 days (range 20-37 days; standard deviation [SD] \pm 6.51 ) and 24.5 days (range 14-35 days; $\mathrm{SD} \pm 8.09$ ) in the experimental and control groups, respectively. Although the time to onset of grade 2 mucositis was slightly delayed in the experimental group compared with the control group, this difference was not statistically significant $(P=0.524)$. Because all patients experienced grade $\geq 2$ mucositis, differences in incidence of grade $\geq 2$ mucositis between the two groups were not analyzed.

In the analysis of the duration of radiation-induced oral mucositis, clove-based herbal mouthwash significantly shortened the duration of grade $\geq 2$ mucositis. The mean duration of grade $\geq 2$ mucositis was 24.3 days (range 12-35 days; SD \pm 8.00$)$ in the experimental group and 37.1 days (range $21-59$ days; $\mathrm{SD} \pm 13.99$ ) in the control group $(P=0.044)$. The clove-based herbal mouthwash also shortened the duration of grade 3 mucositis compared to the duration with clear water. The mean duration of grade 3 mucositis was 5.1 days (range 0-19 days; SD \pm 8.80 ) in the experimental group and 17.7 days (range 0-45 days; $\mathrm{SD} \pm 15.91)$ in the control group. However, this difference was not statistically significant $(P=0.069)$.

The clove-based herbal mouthwash also reduced body weight loss during treatment compared with clear water. The mean reduction ratio of body weight during treatment was $3.1 \%$ (range $0 \%-7.3 \%$; $\mathrm{SD} \pm 2.42$ ) in the experimental group and $7.4 \%$ (range $3.5 \%-10.9 \%$; $\mathrm{SD} \pm 2.98$ ) in the control group, and this difference was statistically significant $(P=0.023)$.

The incidence of supplemental nutrition, maximum pain score, and incidence of RT interruption between the two groups was also analyzed and the results are summarized in
Table 2. These end points were not significantly different between the two groups. No patient experienced side effects from gargling with clove-based herbal mouthwash.

\section{Discussion}

Several studies using different compounds have been performed to identify agents that could minimize or prevent radiation-induced oral mucositis. ${ }^{6-11,26,27}$ However, there is no general agreement on the gold-standard approach for minimization or prevention of radiation-induced oral mucositis, and clinical practice seems to vary among countries and institutions. Palifermin was approved by the US Food and Drug Administration in 2004 for the treatment of chemotherapy-induced oral mucositis in a transplant setting for hematologic malignancies. However, its suitability for the treatment of radiation-induced oral mucositis in head and neck cancer remains to be evaluated. ${ }^{6,28}$ Moreover, there are some concerns about the safety of its use, because of the possibility of stimulation of tumor cells by growth factors. ${ }^{29}$ Herbal drugs can be an alternative to synthetic compounds. Natural products with anti-inflammatory and/or wound healing properties could serve as agents for the prevention or minimization of radiation-induced oral mucositis, and previous studies have shown that several natural products possess beneficial effects suitable for amelioration of radiation-induced oral mucositis. ${ }^{12,13,30,31}$

The clove-based herbal mouthwash in this study is composed of natural products that have been reported to possess anti-inflammatory properties. Even though the process of radiation-induced oral mucositis is not yet fully understood, DNA strand breaks by ionizing radiation, activation of transcription factors (eg, NF- $\mathrm{BB}$ ), and secondary tissue injury 
caused by production of proinflammatory cytokines such as tumor necrosis factor- $\alpha$ (TNF- $\alpha$ ), interleukin (IL)-1, IL-6, and IL- 8 are known to be important steps in the process. ${ }^{32-35}$ Eugenol, the active component of $F$. caryophylli, has been shown to cause significant downregulation of IL-1 in several preclinical studies, ${ }^{15,16,20}$ and $M$. officinalis has been reported to inhibit production of TNF- $\alpha$, NF- $\kappa$ B, IL-1, IL-6, and IL-8. ${ }^{19,22,24}$ In addition, licochalcone, the active component of $R$. glycyrrhizae, has been reported to exert anti-inflammatory effects through downregulation of TNF- $\alpha, \mathrm{NF}-\kappa \mathrm{B}$, IL-1, and IL-6. ${ }^{21,23}$ Fructus schisandrae and H. menthae also have demonstrated anti-inflammatory properties. ${ }^{17,36}$ Moreover, a clinical case report found that chemotherapyinduced oral mucositis was significantly improved after clovebased herbal mouthwash gargling in two cancer patients. ${ }^{25}$ Given this background, we evaluated the efficacy of clovebased herbal mouthwash on radiation-induced oral mucositis in this study. To the best of our knowledge, this is the first study to evaluate the efficacy of clove-based herbal mouthwash on radiation-induced oral mucositis. According to our study, the use of clove-based herbal mouthwash shortened the duration of grade $\geq 2$ mucositis $(P=0.044)$ and reduced body weight loss during RT $(P=0.023)$ compared with the use of clear water. Clove-based herbal mouthwash also reduced the incidence of grade 3 mucositis, supplemental nutrition, and RT interruption, and reduced the duration of grade 3 mucositis and RT interruption. In addition, the clove-based herbal mouthwash delayed the time to onset of mucositis and reduced the maximum pain score, but these differences were not statistically significant. Although, owing to small sample size, we could not find significant differences in some end points, we were able to identify a potentially beneficial role of clovebased herbal mouthwash in the treatment of radiation-induced oral mucositis in patients with head and neck cancer.

There were some limitations in this study. First, this is a preliminary study with small sample size. Second, because the patients were not blinded to their group assignment, possible confounding factors might have been present. Therefore, this study lacks sufficient power to make indisputable conclusions on the efficacy of clove-based herbal mouthwash on radiation-induced oral mucositis and should be validated by further studies. However, the investigator who evaluated patients and their grade of mucositis was blinded throughout this study. In addition, to eliminate possible confounding factors, we excluded patients who received induction chemotherapy or were scheduled to receive concurrent chemotherapy from this study. Because the pathobiology of oral mucositis induced by radiation is different from that induced by chemotherapy, ${ }^{34}$ it was better to include only patients who received RT alone in this study for clear assessment of the efficacy of this particular combination of compounds on radiation-induced oral mucositis.

\section{Conclusion}

Although we could not find significant differences in some end points, this single-blind randomized study showed that a clove-based herbal mouthwash can have a potentially beneficial effect on minimizing or preventing radiation-induced oral mucositis in patients with head and neck cancer. To confirm the results of our study, well-designed randomized studies with large sample sizes will be required.

\section{Acknowledgments}

This research was supported by the Convergence of Conventional Medicine and Traditional Korean Medicine R\&D project funded by the Ministry of Health \& Welfare through the Korea Health Industry Development Institute (KHIDI) (grant no HI14C1723) and the Kyung Hee University Medical Center Research Fund through the Committee for West-East Clinical Research in 2014.

The authors would also like to thank Hyuck Jai Choi, PhD, East-West Medical Research Institute, Kyung Hee University Medical Center, for performing high-performance liquid chromatography analysis for clove-based herbal mouthwash.

\section{Disclosure}

The authors report no conflicts of interest in this work.

\section{References}

1. Rothwell BR. Prevention and treatment of the orofacial complications of radiotherapy. J Am Dent Assoc. 1987;114:316-322.

2. Peterman A, Cella D, Glandon G, Dobrez D, Yount S. Mucositis in head and neck cancer: economic and quality-of-life outcomes. J Natl Cancer Inst Monogr. 2001:45-51.

3. Elting LS, Cooksley CD, Chambers MS, Garden AS. Risk, outcomes, and costs of radiation-induced oral mucositis among patients with head-andneck malignancies. Int J Radiat Oncol Biol Phys. 2007;68:1110-1120.

4. Kong M, Hong SE, Choi J, Kim Y. Comparison of survival rates between patients treated with conventional radiotherapy and helical tomotherapy for head and neck cancer. Radiat Oncol J. 2013;31:1-11.

5. Keefe DM, Schubert MM, Elting LS, et al. Updated clinical practice guidelines for the prevention and treatment of mucositis. Cancer. 2007; 109:820-831.

6. Le QT, Kim HE, Schneider CJ, et al. Palifermin reduces severe mucositis in definitive chemoradiotherapy of locally advanced head and neck cancer: a randomized, placebo-controlled study. J Clin Oncol. 2011;29: 2808-2814

7. Antunes HS, Herchenhorn D, Small IA, et al. Phase III trial of lowlevel laser therapy to prevent oral mucositis in head and neck cancer patients treated with concurrent chemoradiation. Radiother Oncol. 2013;109:297-302. 
8. Hanson WR, Marks JE, Reddy SP, Simon S, Mihalo WE, Tova Y. Protection from radiation-induced oral mucositis by a mouth rinse containing the prostaglandin E1 analog, misoprostol: a placebo controlled double blind clinical trial. Adv Exp Med Biol. 1997;400B:811-818.

9. Leborgne JH, Leborgne F, Zubizarreta E, Ortega B, Mezzera J. Corticosteroids and radiation mucositis in head and neck cancer. A doubleblind placebo-controlled randomized trial. Radiother Oncol. 1998;47: $145-148$.

10. Huang EY, Leung SW, Wang CJ, et al. Oral glutamine to alleviate radiation-induced oral mucositis: a pilot randomized trial. Int $J$ Radiat Oncol Biol Phys. 2000;46:535-539.

11. Rao NG, Trotti A, Kim J, et al. Phase II multicenter trial of Caphosol for the reduction of mucositis in patients receiving radiation therapy for head and neck cancer. Oral Oncol. 2014;50:765-769.

12. Rashad UM, Al-Gezawy SM, El-Gezawy E, Azzaz AN. Honey as topical prophylaxis against radiochemotherapy-induced mucositis in head and neck cancer. J Laryngol Otol. 2009;123:223-228.

13. Rao S, Dinkar C, Vaishnav LK, et al. The Indian spice turmeric delays and mitigates radiation-induced oral mucositis in patients undergoing treatment for head and neck cancer: an investigational study. Integr Cancer Ther. 2013;13:201-210.

14. Kim JS, Park JW, Yoon SW, Ryu BH. Inhibitory effect of respective herbs in Cheonggugamrosu on oral malodor using modeling of the salivary sediment system. J Korean Oriental Med. 2009;30:79-87.

15. Magalhaes CB, Riva DR, DePaula LJ, et al. In vivo anti-inflammatory action of eugenol on lipopolysaccharide-induced lung injury. $J$ Appl Physiol (1985). 2010;108:845-851.

16. Kim SS, Oh OJ, Min HY, et al. Eugenol suppresses cyclooxygenase-2 expression in lipopolysaccharide-stimulated mouse macrophage RAW264.7 cells. Life Sci. 2003;73:337-348.

17. Kang YS, Han MH, Hong SH, et al. Anti-inflammatory effects of Schisandra chinensis (Turcz.) baill fruit through the inactivation of nuclear factor-kappaB and mitogen-activated protein kinases signaling pathways in lipopolysaccharide-stimulated murine macrophages. J Cancer Prev. 2014;19:279-287.

18. Chang YL, Chen CL, Kuo CL, Chen BC, You JS. Glycyrrhetinic acid inhibits ICAM-1 expression via blocking JNK and NF-kappaB pathways in TNF-alpha-activated endothelial cells. Acta Pharmacol Sin. 2010;31:546-553.

19. Walker JM, Maitra A, Walker J, Ehrnhoefer-Ressler MM, Inui T, Somoza V. Identification of Magnolia officinalis L. bark extract as the most potent anti-inflammatory of four plant extracts. Am J Chin Med. 2013;41:531-544

20. Hussain A, Brahmbhatt K, Priyani A, Ahmed M, Rizvi TA, Sharma C. Eugenol enhances the chemotherapeutic potential of gemcitabine and induces anticarcinogenic and anti-inflammatory activity in human cervical cancer cells. Cancer Biother Radiopharm. 2011;26:519-527.

21. Chu X, Ci X, Wei M, et al. Licochalcone a inhibits lipopolysaccharideinduced inflammatory response in vitro and in vivo. J Agric Food Chem. 2012;60:3947-3954.
22. Fu Y, Liu B, Zhang N, et al. Magnolol inhibits lipopolysaccharideinduced inflammatory response by interfering with TLR4 mediated NF-kappaB and MAPKs signaling pathways. J Ethnopharmacol. 2013;145:193-199.

23. Franceschelli S, Pesce M, Vinciguerra I, et al. Licocalchone-C extracted from Glycyrrhiza glabra inhibits lipopolysaccharide-interferon-gamma inflammation by improving antioxidant conditions and regulating inducible nitric oxide synthase expression. Molecules. 2011;16: $5720-5734$.

24. Luo J, Xu Y, Zhang M, Gao L, Fang C, Zhou C. Magnolol inhibits LPS-induced inflammatory response in uterine epithelial cells: magnolol inhibits LPS-induced inflammatory response. Inflammation. 2013;36: 997-1003.

25. Oh HK, Lee JY, Yoon SW. Two cases of advanced cancer patients with the improvement of symptoms using gargling Cheonggugamrosu on FOLFIRI-induced oral mucositis: case series. J Korean Oriental Med. 2014;fal(1):167-173

26. Lievens Y, Haustermans K, Van den Weyngaert D, et al. Does sucralfate reduce the acute side-effects in head and neck cancer treated with radiotherapy? A double-blind randomized trial. Radiother Oncol. 1998;47:149-153.

27. Rahn R, Adamietz IA, Boettcher HD, Schaefer V, Reimer K, Fleischer W. Povidone-iodine to prevent mucositis in patients during antineoplastic radiochemotherapy. Dermatology. 1997;195(Suppl 2):57-61.

28. Henke M, Alfonsi M, Foa P, et al. Palifermin decreases severe oral mucositis of patients undergoing postoperative radiochemotherapy for head and neck cancer: a randomized, placebo-controlled trial. J Clin Oncol. 2011;29:2815-2820.

29. Bossi P, Locati LD, Licitra L. Palifermin in prevention of head and neck cancer radiation-induced mucositis: not yet a definitive word on safety and efficacy profile. J Clin Oncol. 2012:30;564-565.

30. You WC, Hsieh CC, Huang JT. Effect of extracts from indigowood root (Isatis indigotica Fort.) on immune responses in radiation-induced mucositis. J Altern Complement Med. 2009;15:771-778.

31. Das D, Agarwal SK, Chandola HM. Protective effect of Yashtimadhu (Glycyrrhiza glabra) against side effects of radiation/chemotherapy in head and neck malignancies. Ayu. 2011;32:196-199.

32. Sonis ST. Oral mucositis in cancer therapy. J Support Oncol. 2004; 2:3-8.

33. Sonis ST. A biological approach to mucositis. J Support Oncol. 2004; 2:21-32; discussion 35-26.

34. Sonis ST. The pathobiology of mucositis. Nat Rev Cancer. 2004;4: 277-284.

35. Logan RM, Gibson RJ, Sonis ST, Keefe DM. Nuclear factor-kappaB (NFkappaB) and cyclooxygenase-2 (COX-2) expression in the oral mucosa following cancer chemotherapy. Oral Oncol. 2007;43:395-401.

36. Wong RW, Hagg U, Samaranayake L, Yuen MK, Seneviratne CJ, Kao R. Antimicrobial activity of Chinese medicine herbs against common bacteria in oral biofilm. A pilot study. Int J Oral Maxillofac Surg. 2010;39: 599-605.
OncoTargets and Therapy

\section{Publish your work in this journal}

OncoTargets and Therapy is an international, peer-reviewed, open access journal focusing on the pathological basis of all cancers, potential targets for therapy and treatment protocols employed to improve the management of cancer patients. The journal also focuses on the impact of management programs and new therapeutic agents and protocols on
Dovepress

patient perspectives such as quality of life, adherence and satisfaction. The manuscript management system is completely online and includes a very quick and fair peer-review system, which is all easy to use. Visit http://www.dovepress.com/testimonials.php to read real quotes from published authors. 